\title{
Asynchronous Versus Synchronous Learning in Pharmacy Education
}

\author{
Carol A. Motycka ${ }^{1, *}$, Erin L. St. Onge ${ }^{2} \&$ Jennifer Williams ${ }^{3}$ \\ ${ }^{1}$ University of Florida College of Pharmacy, $580 \mathrm{~W} 8^{\text {th }}$ Street, Tower 2, Jacksonville, FL 32209, USA \\ ${ }^{2}$ University of Florida College of Pharmacy, 6550 Sanger Rd, Orlando, FL 32827, USA \\ ${ }^{3}$ University of Florida College of Pharmacy, $9200113^{\text {th }}$ St N, PH Room 102, Seminole, FL 33772, USA \\ *Corresponding author: University of Florida College of Pharmacy, $580 \mathrm{~W} 8^{\text {th }}$ Street, Tower 2, Jacksonville, FL \\ 32209, USA Tel: 1-904-244-9590 E-mail: motycka@cop.ufl.edu
}

Received: December 19, 2012 Accepted: January 17, $2013 \quad$ Online Published: January 28, 2013

doi:10.5430/jct.v2n1p63 URL: http://dx.doi.org/10.5430/jct.v2n1p63

\begin{abstract}
Objective: To better understand the technology being used today in pharmacy education through a review of the current methodologies being employed at various institutions. Also, to discuss the benefits and difficulties of asynchronous and synchronous methodologies, which are being utilized at both traditional and distance education campuses.
\end{abstract}

Setting: Colleges of Pharmacy across the country

Summary: Pharmacy education has seen dramatic changes over the past decade. With the explosion of new technologies come new methods for teaching practitioners. This article describes the various methods being used today to teach our practitioners and the advantages and disadvantages of each method.

Conclusion: The authors conclude that using a blended method of teaching through both asynchronous and synchronous learning produces practitioners ready to take on the new challenges experienced by today's pharmacists.

Keywords: asynchronous; synchronous; pharmacy education; distance education

\section{Introduction}

Distance education is designed to deliver education to students who may not physically be at a specific site. Instead, students and instructors communicate with one another through the use of technology. In recent years, many health profession programs have created distance campus models and currently $20 \%$ of all pharmacy schools have adopted this form of education (Harrison, Congdon, \& DiPiro, 2010). Distance campuses are often created to increase access to major medical institutions, provide greater access of pharmacy education to placebound students, and increase class size. As the trend to develop more distance education campuses continues, it is important to understand the methods by which pharmacists are now being trained, the effectiveness of this model, and the satisfaction of those students completing their degree in this fashion.

The University of Florida College of Pharmacy (UFCOP) was one of the first Colleges of Pharmacy to begin a distance campus program. The University developed three distance education sites for their entry level Doctor of Pharmacy program in the Fall of 2002. One of the initial considerations was whether to utilize synchronous or asynchronous learning. Synchronous learning is defined as simultaneous interaction between 2 or more participants (Ashley, 2003; Cook, Levinson, Garside, Dupras, Erwin, \& Montori, 2008). Examples of synchronous learning include online chat, instant messaging, white boarding, file sharing, audioconferencing, webconferencing, and videoconferencing (Ashley, 2003; Cook et al., 2008). Despite the advantage of "real time" learning, general disadvantages including cost, technology requirements, and scheduling may limit the usefulness of synchronous learning (Ashley, 2003). Cost and consistent information technology (IT) support at each location were considered major disadvantages to using synchronous learning entirely in the UFCOP program. Asynchronous learning allows communication to occur over a period of time, rather than simultaneously. General advantages to asynchronous learning include access to information and resources regardless of time, collaboration amongst groups of individuals 
regardless of time zone, and sharing of collective knowledge. However, asynchronous learning requires one to be self-disciplined and tends to be less personal than synchronous learning (Ashley, 2003). Examples of asynchronous learning include discussion boards, web blogs, email, streaming audio, streaming video, narrated slide shows, web-based training, databases, web books, surveys, shared calendars, and website links (Ashley, 2003).

A review of the literature indicates distance education utilizing synchronous and asynchronous learning is occurring within various institutions. The purpose of this article is to review the literature highlighting advantages and disadvantages of both forms of learning in order for educators to understand the method in which pharmacy students are being trained today.

\section{Synchronous Learning}

Videoconferencing is one form of synchronous learning which allows "real time" interaction between instructors and students. Videoconferencing may reduce time and travel costs for faculty and students, and also allows the introduction of several different teaching aids such as computers and CD-ROMs. From an educational perspective, videoconferencing may be used for meetings (ex: supervision of research students from various locations), teaching (ex: case study between instructor and various students), management (ex: committees or organizations at various campuses), or interviewing (ex: oral examinations). Modern videoconferencing systems can receive input from almost any other digital system and can be accomplished using videophones, plug-in cards for personal computers (PCs), or tabletop videoconferencing systems (Reynolds, 2008).

Distributed tutored video instruction (DTVI) is another form of synchronous learning which has been utilized to teach distance education (Cadiz, 2000). DTVI involves students in multiple locations "meeting" to watch and discuss pre-recorded lectures. Advantages to DTVI include the ability to include students in different locations, and allow many small groups to exist and make progress independently. Although the UFCOP does not schedule DTVI sessions, students have formed their own DTVI groups to watch pre-recorded lectures and discuss the lecture material amongst themselves.

EClass is another form of synchronous learning. A course which utilizes EClass is conducted in the same manner as a standard lecture, however, after class a series of web pages is created which incorporates the audio, video, visited websites, and lecture slides. The creation of these webpages allows students to access the lecture, print out slides, or search for related material (Brotherton, 2004).

UFCOP has utilized Elluminate ${ }^{\circledR}$, a form of synchronous learning. It is an online learning platform which allows faculty and students to communicate using headphones and their computer. The platform allows for live voice interactions, whiteboard communication, chat messaging, and content sharing.

\section{Asynchronous Learning}

Mobile learning (mLearning) is a form of asynchronous learning that makes use of portable wireless technologies such as media players (mp3, iPod), smart phones (Blackberry, iPhone), and personal digital assistants (PDAs). mLearning makes course material portable, therefore, students can take advantage of any unexpected free time. A form of mLearning called Podcasting allows students to download broadcasts published to the internet on a portable device which can then be watched at the student's convenience (Evans, 2008).

Bell and colleagues report on a system called the Canterbury 'Digital Lectures' system. The purpose of this form of asynchronous learning is to automatically capture and index lecture content which then allows for flexible delivery of course content. This system is beneficial to students in that there is no requirement to be in a certain place at a specific time. It was also designed such that instructors were not required to alter their teaching methods (Bell, 2001).

The University of Florida captures all of the lecture content using a company called Classroom 24-7. The lectures are uploaded to Sakai, a course management system, and made available to all students 2 to 3 hours after completion. Students are able to watch the lectures in the same method one would watch a movie on their DVD player including pausing, rewinding and fast forwarding, changing the speed, and reviewing the lecture material at any time they wish during the semester. This type of flexibility allows students to have more control over their learning. 


\section{Assessing Outcomes}

When deciding whether to use synchronous or asynchronous learning in distance education, several outcomes should be considered. Student satisfaction is important as it reflects the student's reaction to online education. Faculty satisfaction is equally important in order to recruit and maintain the brightest and best individuals. Assessment of student knowledge is important in determining their factual or conceptual understanding of the material presented. Other outcomes that are important to assess are student's skills (ability to perform a specific procedure or technique) and behaviors (Cook et al., 2008).

\subsection{Student and Faculty Satisfaction}

Student satisfaction with asynchronous and synchronous learning is an important endpoint to measure when implementing a distance education program. In order to have an understanding of student preferences and satisfaction for learning, we approached the literature with the question of whether or not students are more satisfied with asynchronous or synchronous learning. In general, a purely asynchronous or blended approach to learning provided students with more satisfaction than synchronous learning alone.

Streaming video, a form of asynchronous learning, was implemented in a pilot section of a course at the University of Buffalo-State University of New York (Simpson, 2006). Student responses to the question "why this method of obtaining lecture material was preferred" included "I can schedule my time to see lectures", "Repeat function is good for me to clarify some concepts I do not understand", and "Pause allows me to check the word I do not know immediately". Other students stated "I learn very little in a typical classroom setting. I am easily distracted...". Data regarding student satisfaction was obtained from students in the asynchronous pilot section and the traditional lecture based section. Compiled results from the survey based on a likert scale of 1 to 5 , revealed students within the asynchronous group were more stimulated in the course ( 4.23 vs. 3.99$)$, worked more often within study groups (4.43 vs. 3.18), felt the instructor's teaching was more effective (4.46 vs. 4.21$)$, and rated the course overall better than those students in the traditional group (4.21 vs. 4.03).

Satisfaction with asynchronous learning in regards to perceived effectiveness of the course, was noted in a study by Hubble (2006). Paramedic students were given the option to complete a course via a traditional classroom setting or online. The students who completed the course online were asked to complete a survey comparing their course to a traditional course. The survey was based on a likert scale from 1 to 9 asking them to compare how they liked the online course to a traditional course with 1 indicating much less than a traditional course, 5 indicating about the same, and nine inidicating much more. Although students indicated they spent more time on the online course (7.45), they believed the course taught them more than a traditional live lecture based course (6.80). An interesting result from this study was that students felt they received better interaction with the instructor during the online course than with a traditional course (7.65).

A study at Brunel University revealed that podcasting increased student satisfaction because of the flexibility inherent in this form of learning (Evans, 2008). Overall students felt podcasting enhanced their learning process and offered an efficient and effective method for teaching. Similar results were found in a study completed at the University of Southampton. In a survey regarding the use of podcasting, $93 \%$ of respondents indicated they would like to see more use of this technology (Copley, 2007).

Student satisfaction with web-based learning was studied by Newlin, et al (2005). In this study, students were randomized to complete a course in a conventional lecture group, a synchronous web-based group, or an asynchronous web-based group. At the conclusion of the course, students in each group were asked a series of questions regarding their satisfaction with their course experience. Students in the web based groups responded more positively to the questions regarding whether they learned the material $(p<0.05)$, enjoyed the course $(p=0.21)$, and would take the course again $(\mathrm{p}<0.01)$.

A study conducted at UCLA compared students in an internet based course to students in the same course in a traditional format (Woo, 2000). Results showed no significant difference in student satisfaction $(\mathrm{p}=0.36$ ), however, the students in the internet group felt as though they were more stimulated by their learning experience $(\mathrm{p}=0.04)$. The authors concluded that this may be the result of students feeling more in control of their learning.

Satisfaction with asynchronous learning has been observed not only in students, but in faculty and administrators as well. This method of learning allows access to a wider range of students including those that are disabled or place-bound. It also allows flexibility for faculty and decreases classroom space requirements (Newlin, 2005). In a study by Bennett and Glover, lecturers were asked about their experience with video streaming versus in classroom lecturing (2008). Faculty comments included decreased travel time to rural areas, the ability to self assess their 
lectures by reviewing the videos, and the decreased need for repeating lectures to several classes. General satisfaction by faculty has also been noted at the University College London and Georgia Institute of Technology where eClass was introduced (Brotherton, 2004).

Even though skepticism to asynchronous learning remains, several investigators have concluded that when students have control over their learning they are more satisfied and will therefore be more motivated to learn. Given the fact that students crave autonomy, yet still desire a valuable learning experience, the development of blended learning has become important. A blended learning approach provides information both via asynchronous methods, such as purely didactic lectures delivered via streaming video, and synchronous methods, such as active learning within the classroom setting. Blended learning satisfies the students need for face-to-face interaction with both fellow students and faculty while providing them a certain level of autonomy (Riffell \& Samuel, 2004).

In a study at Texas Tech University, students within a Pharmacy course utilizing asynchronous, synchronous, and blended learning were asked questions in regards to satisfaction with the course. Nearly $90 \%$ of students preferred the blended or synchronous method of learning as opposed to strictly asynchronous learning (Moridani, 2007).

\subsection{Student Knowledge, Skills, and Behaviors}

A recent study at the University of Missouri School of Health Professions compared a traditional teaching model to a blended model of instruction. The two classes were taught by the same faculty member. No significant difference was found between the two classes in academic achievement $(\mathrm{p}=0.05)$ or student satisfaction $(\mathrm{p}=0.05)$. The authors concluded that blended learning was at least equivalent to a traditional model based on these outcomes (Nagel, 2008).

Researchers at the University of North Dakota investigated the use of online lecture resources and their effect on examination performance and class attendance in two introductory psychology courses (Grabe, 2007). Online lecture resources included outline notes, complete notes, and lecture audio. Class attendance was measured by completion of three in-class writing assignments given on unannounced dates. Each time a student logged on to access data, the information was recorded in a log file. Only $3 \%$ of students accessed the audio files while $61 \%$ accessed the available outline notes. When comparing the correlation between the use of online lecture resources and attendance on examination performance, it was found that attendance and use of online resources was significantly related to performance on the first two examinations in the course. The researchers in this study concluded that decreased attendance was not a direct result of providing online lecture resources, but that the availability of online lecture resources may have been of benefit to students who were absent from class. The low use of the audio content was hypothesized to be due to the availability of complete lecture notes online (Grabe, 2007).

\section{Conclusion}

After much consideration, the University of Florida College of Pharmacy decided on a blended approach to learning, utilizing both asynchronous and synchronous learning. Faculty felt strongly that in order to create a well rounded pharmacist, yet provide opportunities to placebound students and increase student satisfaction, this blended form of learning was necessary. When the distance education program was first implemented at the UFCOP, many people were skeptical about the quality of education a distance education student in a professional program would receive. Analyses of exam scores, graduation rates, and scores on the Pharmacy licensing exam (NAPLEX) have shown all campuses to be equal. This helped clarify the question of whether student outcomes would be compromised utilizing both asynchronous and synchronous learning. In regards to student satisfaction, we have discovered that although students at the main campus are given the opportunity for synchronous learning of material through attending live lectures, the majority of those students choose not to do so as they are satisfied with the form of asynchronous learning utilized. We believe this is in large part due to the fact that we continue to offer opportunities for synchronous learning through live interactions such as laboratory sessions and discussion of cases as well as technologies such as Elluminate ${ }^{\mathbb{B}}$ and videoconferencing. Student outcomes and satisfaction will continue to be monitored as the program evolves.

With distance education continuing to expand to more Colleges of Pharmacy across the country, it is important to understand the advantages as well as some of the challenges to this form of learning. Young graduates are part of the Generation Y (Millenials) who appear to demand education be more flexible. This must be balanced, however, with the realization that pharmacists need professionalization and in class skill building including communication, laboratory, and critical thinking. 


\section{References}

Ashley, J. (2003). Synchronous and Asynchronous Communication Tools. ASAE and the center for association leadership. Retrieved

from http://www.asaecenter.org/PublicationsResources/articledetail.cfm?ItemNumber=13572

Bell, T. (2001). Flexible Delivery Damaging to Learning? Lessons from the Canterbury Digital Lectures Project. Presented at the World Conference of Educational Media, Hypermedia, and Telecommunications, June 25 - 30, in Tempere, Finland. 117-22.

Bennett, P. (2008). Video Streaming: Implementation and Evaluation in an Undergraduate Nursing Program. Nurse Education Today, 28, 253-58. http://dx.doi.org/10.1016/j.nedt.2007.04.005

Brotherton, J.A. (2004). Lessons Learned From eClass: Assessing Automated Capture and Access in the Classroom. ACM Transactions on Computer-Human Interaction, 11, 121-55. http://dx.doi.org/10.1145/1005361.1005362

Cadiz, J.J. (2000). Distance Learning Through Distributed Collaborative Video Viewing. Computer Supported Cooperative Work, 135-44.

Cook, D.A., Levinson A.G., Garside, S, Dupras, D.M., Erwin, P.J., \& Montori, V.M. (2008). Internet Based Learning in the Health Professions. JAMA, 300(10), 1181-96. http://dx.doi.org/10.1001/jama.300.10.1181

Copley, J. (2007). Audio and Video Podcasts of Lectures for Campus-Based Students: Production and Evaluation of Student Use. Innovations in Education and Teaching International, 44, 387-99. http://dx.doi.org/10.1080/14703290701602805

Evans, C. (2008). The Effectiveness of m-Learning in the Form of Podcast Revision Lectures in Higher Education. Computers and Education, 50, 491-98. http://dx.doi.org/10.1016/j.compedu.2007.09.016

Grabe, M. (2007). Optional Student Use of Online Lecture Resources: Resource Preferences, Performance and Lecture Attendance. Journal of Computer Assisted Learning, 24, 1-10. http://dx.doi.org/10.1111/j.1365-2729.2007.00228.x

Harrison, L.C., Congdon, H.B., \& DiPiro, J.T. (2010). The Status of US Multi-campus Colleges and Schools of Pharmacy. Am J Pharm Educ, 74(7). http://dx.doi.org/10.5688/aj7407124

Hubble, M.W. (2006). Paramedic Student Performance: Comparison of Online with On-Campus Lecture Delivery Methods. Prehospital and Disaster Medicine, 21, 261-67.

Moridani, M. (2007). Asynchronous Video Streaming vs. Synchronous Videoconferencing for Teaching a Pharmacogenetic Pharmacotherapy Course. American Journal of Pharmaceutical Education, 71(1), 16. http://dx.doi.org/10.5688/aj710116

Nagel, D. (2008). Is Blended Learning Effective? Campus Technology. Retrieved from http://campustechnology.com/Articles/2008/09/Is-Blended-Learning-Effective.aspx?Page=1

Newlin, M. (2005). An Experimental Comparison of Conventional and Web-based Instructional Formats. North American Journal of Psychology, 7, 327-36.

Reynolds, P.A. (2008). Seeing is Believing: Dental Education Benefits from Developments in Videoconferencing. British Dental Journal, 204, 87-92. http://dx.doi.org/10.1038/bdj.2008.9

Riffell, S.K. (2004). Can Hybrid Course Formats Increase Attendance in Undergraduate Environmental Science Courses? J Nat Resour Life Sci Educ, 33, 16-20.

Simpson, N. (2006). Asynchronous Access to Conventional Course Delivery: a Pilot Project. British Journal of Educational Technology, 37, 527-37. http://dx.doi.org/10.1111/j.1467-8535.2006.00534.x

Woo, M.A. (2000). Comparison of Internet Versus Lecture Instructional Methods for Teaching Nursing Research. Journal of Professional Nursing, 16, 132-39. http://dx.doi.org/10.1053/PN.2000.5919 